\title{
Modelling the Relationships between Train Commuters' Access Modes and Traffic Safety
}

\author{
Duc C. Phan $\mathbb{D}^{1},{ }^{1}$ Long T. Truong $\mathbb{D},{ }^{1}$ Hien D. Nguyen $\mathbb{D}^{2},{ }^{2}$ and Richard Tay $\mathbb{D}^{3}$ \\ ${ }^{1}$ School of Engineering and Mathematical Sciences, La Trobe University, Melbourne, Australia \\ ${ }^{2}$ School of Mathematics and Physics, The University of Queensland, Brisbane, Australia \\ ${ }^{3}$ School of Accounting, Information Systems and Supply Chain, RMIT University, Melbourne, Australia \\ Correspondence should be addressed to Long T. Truong; l.truong@latrobe.edu.au
}

Received 26 August 2021; Revised 4 January 2022; Accepted 18 January 2022; Published 26 February 2022

Academic Editor: Hongtai Yang

Copyright (C) 2022 Duc C. Phan et al. This is an open access article distributed under the Creative Commons Attribution License, which permits unrestricted use, distribution, and reproduction in any medium, provided the original work is properly cited.

Walking, cycling, and feeder bus/tram for first- and last-mile (FLM) train access are often considered to have better health benefits, lower cost, and less environmental impacts than driving. However, little is known about the road safety impacts of these FLM access modes, particularly at a network level. This paper aims to investigate the impacts of train commuters' access modes on road safety in Victoria, Australia. Macroscopic analyses of crash outcomes in each zone (i.e., Statistical Area Level 1) were performed using negative binomial (NB) and spatially lagged X negative binomial (SLXNB), accounting for potential indirect effects of mode shares in adjacent zones. This macroscopic analysis approach enabled the consideration of the safety effects across the network. The results showed that the SLXNB models outperformed the NB models. Commuting by train, either with walking or car as FLM access mode, was negatively associated with both total and severe crashes. In addition, commuting by train with feeder bus/tram access mode was negatively associated with severe crashes. Interestingly, commuting by train with cycling access mode was negatively associated with total crashes, with a larger effect when compared to walking and car access modes. Overall, the results suggested promoting active transport as FLM train access mode would lead to an improvement in road safety.

\section{Introduction}

Public transport is widely known as a sustainable transportation mode that reduces congestion and air pollution [1]. In recent research, public transport travel (bus, tram, or train) has also been shown to have road safety benefits at a network level $[2,3]$. However, public transport travel often includes a multimodal trip with a main public transport mode and one or several access modes for first- and last-mile (FLM) connections. Those public transport access modes may include walking, feeder bus/tram [4], cycling [5-7], or driving (e.g., park-n-ride and kiss-n-ride) [8-10].

Improving these access modes may increase the use of public transport, hence providing overall safety benefits. However, these access modes may have different safety implications. For example, unlike feeder bus/tram, walking and cycling to public transport stops/stations may have increased risks because active transport users are widely known as vulnerable road users [11]. Yet, it remains unclear as to what extent the promotion of active transport as FLM public transport access mode would affect road safety at a network level. Furthermore, in terms of public transport access, walking, cycling, and feeder bus/tram are usually promoted in place of car travel, due to their health benefits, low travel cost, low energy consumption, less pollution, and lack of parking requirements $[5,12,13]$. From a policy perspective, it is essential to understand if promoting active transport for public transport access can lead to a synergistic effect on road safety, public health, the environment, and the economy.

Many countries are facing road safety issues, including developed countries such as Australia, in which the state of Victoria is not an exemption [14]. Increasing public transport use is one of the major road safety strategies, especially in the state of Victoria, where the integration of walking, cycling, and feeder bus/tram with public transport 
is strongly promoted [15-18]. Indeed, the Victorian Road Safety Action Plan 2021-2030 [19] proposes to investigate the safety issues associated with accessing public transport, emphasizing a gap in understanding the safety of public transport access modes.

In Victoria, the train system consists of two main networks, including the metropolitan train network and the regional train network. The metropolitan train network, i.e., Metro trains, includes 17 lines, connecting suburbs within Melbourne metropolitan area. The regional train network, i.e., V/Line, includes 7 lines, linking Melbourne with other Victoria's regional areas and other states. Train commuting has the largest share when compared to other public transport modes, with a $10.1 \%$ share of the total commuting trips in 2016 compared to $1.3 \%$ by bus and $2.3 \%$ by tram [20]. Furthermore, FLM modes for train access have been fairly diversified, with $68.93 \%$ walking, $16.13 \%$ using a feeder bus/tram, $0.42 \%$ cycling, $12.67 \%$ driving, and $1.75 \%$ riding as a car passenger. On the other hand, walking is the predominant FLM public transport access mode for bus and tram, with $89.45 \%$ and $97.21 \%$, respectively [20]. It is noted that these figures were calculated from the aggregation of mode share data at Statistical Area Level 1 (SA1). Due to the perturbation process [21], the final results may have some slight differences when using other zonal systems.

This paper aims to investigate the relationships between train commuters' access modes, particularly by active transport, and traffic safety, using a case study of Victoria, Australia. Since variations in travel mode shares in one area might affect traffic and thus safety in nearby areas and potentially other parts of the network, it is essential that safety analyses are conducted at a network level, using macroscopic or zonal crash prediction models. Unlike previous macroscopic studies that look at the direct safety effect of mode shares in each zone, this study will utilize spatially lagged X negative binomial regression (SLXNB) to explicitly consider the indirect effects of mode shares from neighboring zones on the safety of a particular zone.

The paper is structured as follows. A literature review is presented in Section 2, followed by descriptions of data and methods in Section 3. Modeling results are then reported in Section 4, followed by a discussion of key results and policy implications in Section 5.

\section{Literature Review}

2.1. Public Transport's Access Modes and Safety. Walking and cycling are widely considered sustainable FLM access modes for public transport. Walking is a common mode of shortdistance connection to train stations with a catchment size below one kilometer [22]. Previous studies have shown that walking would not only help to reduce travel costs, road congestion, and environmental impacts but also would have health benefits $[23,24]$. For example, Cervero [5] argued that converting train access trips from car to walking might reduce vehicle-distance-travelled, air pollution, energy consumption, noise level, and free up parking lot land for infill development. Besser and Dannenberg [25] found that the recommended daily physical activity duration for US residents could be accomplished by walking to/from public transport.

In terms of longer FLM connection distances, previous studies have often promoted bicycles over cars [12, 13]. For example, Replogle [13] found bike-and-ride to be a more economical policy compared to park-and-ride in Japan, the Netherlands, Germany, Denmark, and the US, because it reduced energy consumption, reduced pollution, and had less space requirement. Similarly, Martens [26] stated that FLM access by cycling would bring several environmental and societal benefits over car usage, such as reducing energy consumption, noise pollution, air pollution (especially related to car's cold starts), and road congestion, and may strengthen the economic performance around public transport. Additionally, previous research has found that an increase in cycling activity for FLM public transport access may create health benefits and more livable communities [27]. Cycling for FLM public transport access was also found to increase job accessibility for public transport users $[28,29]$.

However, little research has directly looked at the relationships between traffic safety and walking and cycling as FLM public transport access modes at a network level. Extant research has indicated that pedestrians and cyclists are vulnerable road users [11], and active transport has a higher risk of crashes than car travel. For example, based on the road casualties data from French national police in 2007 and 2008, cyclists' fatality risk was $50 \%$ higher than that of car users [30]. Higher active transport mode share was also associated with increasing road crashes in road safety analyses at a macroscopic level [31, 32]. Previous studies have also found clusters of pedestrian crashes around bus stops $[33,34]$ or subway stations [35]. These findings might suggest that increasing public transport access by active transport may offset the safety benefits of using public transport.

On the other hand, there is evidence that increasing the use of active transport, as the main travel mode, could lead to a positive marginal effect on traffic safety through the 'safety in numbers' phenomenon [36, 37]. For example, Jacobsen [38] reported the effect of 'safety in numbers' where active commuting modes were associated with a significant reduction of pedestrian and cyclist casualty rates in California, USA. Nevertheless, it remains uncertain as to what extent the promotion of active transport as FLM access modes would affect the road safety benefit at a network level.

Feeder public transport service, particularly feeder bus and tram, has been suggested as a solution to increase train ridership [39-41] and also a sustainable feeder mode [42]. For example, compared to park-and-ride, Cervero [5] stated that promoting bus-and-ride in the US, particularly in the suburbs, could bring more economic and environmental benefits such as less parking lot requirement, and thus saving cost and land used. In addition, vehicle-miles-travelled could also be reduced, hence, decreasing greenhouse gas emissions, energy consumption, and noise level.

Previous safety research has often looked at bus and tram as main travel modes. For example, Truong and Currie [3] found the percentages of people commuting by bus and by 
tram were negatively related to the total and severe crashes in Melbourne at a zonal level. Among the limited research on safety-related issues of public transport as a feeder mode, Guo et al. [43] found that the perception of metro users toward vehicle-related crash risks encouraged them to use buses as a feeder mode, instead of walking access and egress to/from the metro station in Shenzhen, China. Overall, the associations between traffic safety and bus/tram trips as a feeder link in multimodal train commuting travel have not received enough attention in existing research.

2.2. Macroscopic Crash Prediction Models. Macroscopic crash prediction models (MCPM) have been developed to explore the relationships between the safety outcomes of a zone and its zonal characteristics. Many zonal levels have been considered, such as traffic analysis zones, counties, and statistical areas [44-46]. The numbers of total crashes and fatal/serious injury crashes (severe crashes) have often been used as safety outcomes in MCPMs [47, 48].

Transport mode shares have been used as explanatory variables in MCPMs, including public transport and active transport mode shares. For example, it was reported that the proportion of commuting trips using public transport was correlated with the increase in the expected number of vehicular crashes, nonmotorized crashes, and fatal vehicular crashes in Chicago, USA [49]. However, a recent multimodal analysis, characterizing the safety benefits of all public transport modes at a network level in Melbourne, Australia, showed that commuting by train, bus, and tram might decrease total and severe crashes [3]. In addition, a rise in the active transport mode share for commuting would result in more crashes for bicyclists and pedestrians [31]. Likewise, Moeinaddini et al. [2] observed the negative effect of motorcycling commuters on road fatality rates among several European cities.

Since a single trip can go through multiple zones, there may be spatial correlations between the mode shares in one zone and crashes in neighboring zones. These spatial correlations in MCPMs can be considered using spatial regression models such as spatial lag Y models [50-52] or spatial error models [52-54]. The spatial lag $\mathrm{Y}$ model considers the correlation of crashes between neighboring zones and the spatial error model explores the spatial autocorrelation effect. However, to capture the spatial correlations of independent variables (such as travel mode share), the spatially lagged X (SLX) model should be used [55]. There is limited research using the SLX models to explore the relationships between traffic safety and mode shares. Therefore, the SLX modeling approach was used in this study to capture the spatial correlation (indirect effect) of the mode share variables. Moreover, to account for data overdispersion, negative binomial regression was considered in the SLX model.

A range of sociodemographic, road network, and land use variables can be used as explanatory variables in MCPMs. The population has often been utilized as an exposure variable, assuming that a higher number of people would be associated with more travel activities [56, 57].
Sociodemographic variables such as the proportion of young age group under 15 years old are negatively correlated with the crash rate [58]. Besides, it was reported that a higher unemployment rate would be associated with decreasing crashes and crash severity $[59,60]$.

Among the road network characteristics, Tasic and Porter [49] found that the percentage of expressways and arterial roads in a road network was positively correlated with the number of total vehicular crashes and fatal vehicular crashes. Regarding the public transport stops' safety, a positive correlation between crashes and the amount of Seoul's subway/ bus stops was observed [58]. In addition, a higher tram stops density would result in more tram crash likelihood in Melbourne, Australia [61]. Similarly, signalized intersections were correlated with more crashes [62]. Land use was also found to influence road crashes. For example, Pulugurtha, Duddu, and Kotagiri [63] discovered a strong positive correlation between crashes and mixed-use developments. In contrast, land use entropy is negatively correlated with severe pedestrian crash rates in Austin, Texas, USA [64].

\section{Data and Methods}

3.1. Data. Data were gathered from several public sources, such as the Australian Bureau of Statistics (ABS) census data [20] and Victorian government open data (DataVic) [65]. The ABS census data are summarized by different statistical areas based on the Australian Statistical Geography Standard (ASGS) [66]. ASGS is a nested hierarchy where multiple zones at the same level can be aggregated to the next level. In this system, the smallest geographic unit is Mesh Blocks which contain 30 to 60 dwellings. Mesh Blocks can be combined to create the SA1 level, which has a typical population of 200 to 800 people. The next levels are SA2, SA3, and SA4, where having populations range from 3,000 to over 100,000 people. The final levels are States and Territories level and the country level. The SA1 level was selected as the unit of this analysis to reduce the loss of information due to the aggregation at higher levels and the noise from the perturbation process compared to Mesh Blocks [21]. All collected data were aggregated at the SA1 level. The average size of SA1 in Victoria is $15.2 \mathrm{~km} 2$, and in Greater Melbourne (Melbourne metropolitan area) is $0.9 \mathrm{~km}^{2}$. There are a total of 14,073 zones in Victoria. However, after removing all offshore or zero population zones (e.g., airport, forest), 13,768 zones remained in the Victoria region, in which 10,059 zones belong to Greater Melbourne.

The shares of commuting by different modes were derived from the multimodal journeys of train commuters. In this study, the main independent variables are the shares of commuting by train with different FLM access modes (walking, feeder bus/tram, cycling, and car). Note that data on other commuting modes included bus, tram, walk, bicycle, motorcycle, and car (including car as driver and car as a passenger). It is also noted that motorcycles included motorbikes, motor scooters, and mopeds. As there was no information about electric cars, motorcycles, or bicycles, it was not possible to consider these modes separately. Other commuting modes such as ferry, truck, taxi were negligible. 
A list of zonal characteristics was selected or computed from the census data based on the literature review. Census data included the standard sociodemographic characteristics such as population, proportion of young age group from 0 to 14 years old, proportion of unemployment, and land use mixed entropy. Other transport networks and infrastructure variables were obtained from DataVic, including the proportion of freeway and arterial network, number of signalized intersections, number of train stations, and number of bus and tram stops.

The land use entropy was calculated from the mixture level of five land types (commercial, civic, industrial, residential, and parkland) as follows:

$$
L U_{i}=-\frac{\sum_{c=1}^{n_{i}} p_{i c} \ln \left(p_{i c}\right)}{\ln \left(n_{i}\right)},
$$

where $L U_{i}$ is the land use entropy in zone $i$, the percentage of land use type $c$ in zone $i$ is $p_{i c}$, and $n_{i}$ is the count of land types in zone $i$. The land use entropy receives a value between 0 and 1 . A land use entropy closer to one signifies a greater mixed land use.

Crash data over the five years from 2014 to 2018 in Victoria from DataVic were extracted from the database containing the police-reported crashes that are available at DataVic and mapped to the SA1 zones using ArcGIS 10.7 [67]. The numbers and rates of total crashes and severe crashes (including fatalities and serious injuries) were calculated for each SA1 zone. Figures 1 and 2 show the average annual total crash and severe crash rates per 1,000 residents at SA1 zones in Victoria and Greater Melbourne, respectively.

Regarding the commuting data, due to the concentration of the population and jobs in Melbourne, most of the train commuters use metropolitan train services. Figure 3 illustrates the distribution of train commuters across SA1 zones in Victoria and Greater Melbourne. In general, train commuters were concentrated around the Melbourne metropolitan train lines.

The values of the mean, standard deviation, min and max for all selected variables for Victoria and Greater Melbourne at the SA1 level are presented in Table 1.

3.2. Methods. The variance inflation factor (VIF) was utilized to inspect the multicollinearity between explanatory variables. Severe multicollinearity may exist when the VIF value exceeds 10 [68]. Multicollinearity was also checked using the Spearman's and Pearson's correlation tests.

The Moran's I test [69] of spatial correlations among travel mode shares in neighboring zones was conducted using spdep package [70] in R [71]. The spatial weight matrices for Moran's I test were defined using standardized queen contiguity, similarly to the spatial weight matrices for spatially lagged $\mathrm{X}$ negative binomial regression models below.

Negative binomial models and spatially lagged $\mathrm{X}$ negative binomial models were used in this analysis. Eight macroscopic crash prediction models were developed, including four NB models and four SLXNB models, for total crashes and severe crashes in the whole of Victoria and
Greater Melbourne. Akaike information criterion (AIC) value and likelihood ratio test were used for model comparison.

3.2.1. Negative Binomial (NB) Model. The dependent variables in this model are count data and therefore, using the Poisson models is appropriate. Poisson distribution, however, assumes that the mean and variance of the crash frequency are equal. Since overdispersion was detected in our data, the negative binomial model [72] is applied in this study:

$$
\begin{aligned}
y_{i} \mid \lambda_{i} & \sim \operatorname{Poisson}\left(\lambda_{i}\right), \\
\operatorname{Ln}\left(\lambda_{i}\right) & =X_{i} \beta+\varepsilon_{i},
\end{aligned}
$$

where $y_{i}$ is the observed number of crashes in zone $i$, and $\lambda_{i}$ is the expected number of crashes in zone $i . X_{i}$ is a vector of explanatory variables. $X_{i}$ includes the $\log$ of the population used as an exposure variable. It is noted that the use of the population as an acceptable exposure variable was demonstrated in previous macroscopic safety analyses, incorporating mode shares $[2,31]$. Furthermore, $\beta$ is a vector of the coefficient (direct effect) associated with explanatory variables, $\varepsilon_{i}$ is the model disturbance term, and $\exp \left(\varepsilon_{i}\right)$ is Gamma distributed with a mean 1 and a variance $1 / \theta$, where $\theta$ is the dispersion parameter.

\subsubsection{Spatially Lagged $X$ Negative Binomial Regression} (SLXNB) Model. The SLXNB model is derived by extending the NB model with a spatial lag component as follows:

$$
\operatorname{Ln}\left(\lambda_{i}\right)=X_{i} \beta+W_{i} X \Phi+\varepsilon_{i},
$$

where $W_{i}$ is a vector of spatial weights, $\Phi$ is a vector of the spatial autoregressive parameter (indirect effect) for explanatory variables, and $X$ is a matrix of explanatory variables for all zones. The spatial weight vector is defined using standardized queen contiguity. All neighboring zones that share at least a border or a corner point with zone $i$ receive a value of one divided by the number of neighboring zones (1/number of neighbouring zones) and zero otherwise.

The indirect effects of all mode share variables are explored using SLXNB models. As the result of the SLXNB models, each of these modes generated direct (local) effects and indirect (lag) effects. The total effects were then calculated considering both effects. The NB models and SLXNB models were developed in the $\mathrm{R}$ programming environment [71]. The NB model estimation was performed using glm.nb function directly [73]. On the other hand, the SLXNB models were estimated in two steps. First, lmSLX function in spatialreg package [74] was used to calculate the lag components for mode share variables. Next, glm.nb function was employed for model estimation. The maximum likelihood fitting method was used for all models. The total effects of mode share variables were calculated using multcomp package [75] in $\mathrm{R}$.

\section{Results}

The likelihood ratio test indicated that the two NB models (Tables 2 and 3) and dispersion parameters were highly significant $(p<0.001)$. However, lower AIC values 


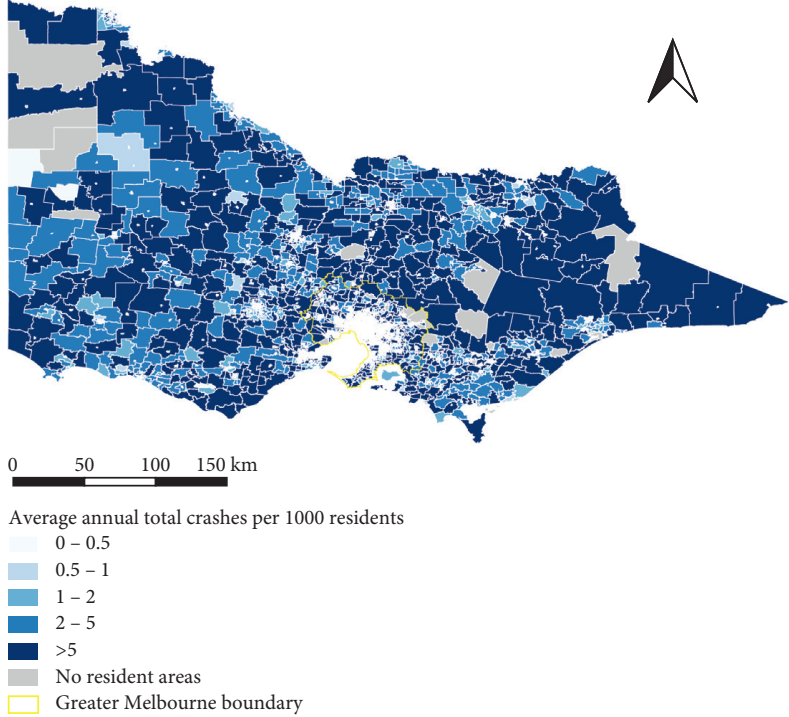

(a)
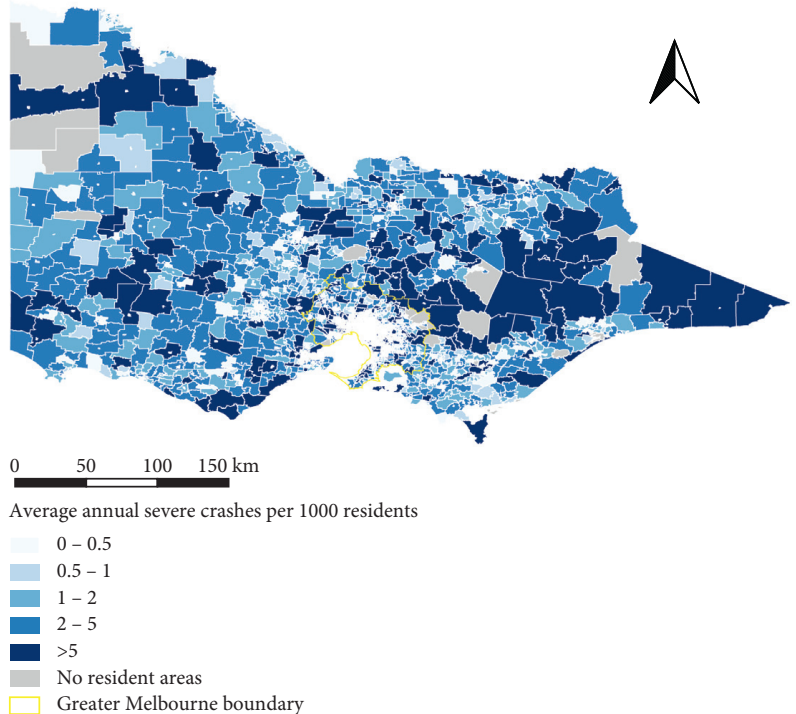

Greater Melbourne boundary

(b)

Figure 1: Average annual crash rates per 1,000 residents at SA1 zones in Victoria. (a) Total crashes per 1000 residents. (b) Severe crashes per 1000 residents.
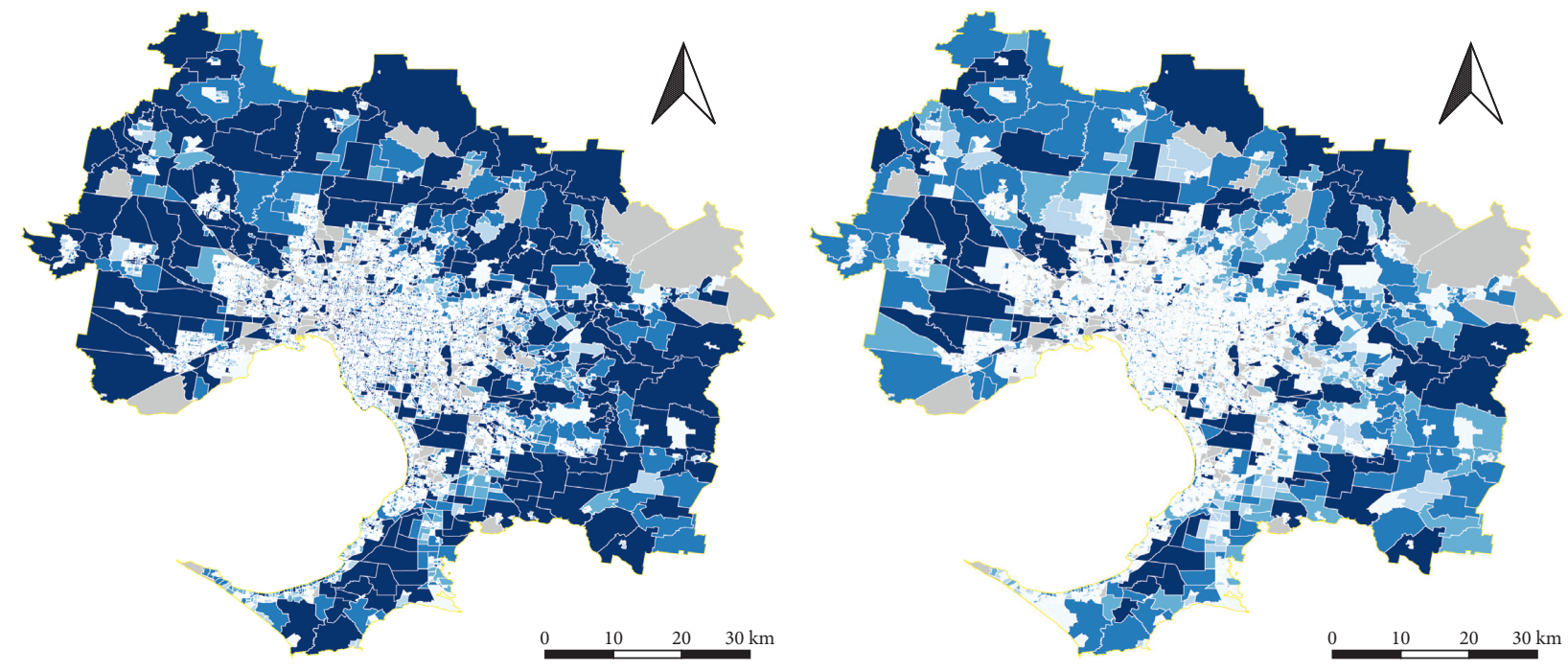

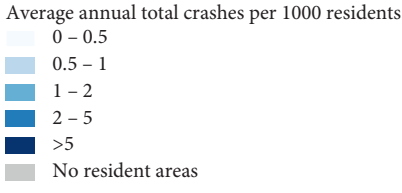

(a)

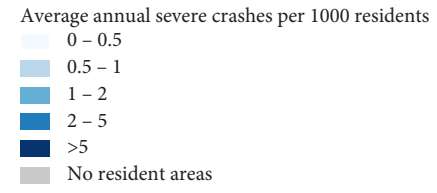

(b)

Figure 2: Average annual crash rates per 1,000 residents at SA1 zones in Greater Melbourne. (a) Total crashes per 1000 residents. (b) Severe crashes per 1000 residents.

implied that the SLXNB models (Tables 4 and 5) had a better fit in comparison with the NB models. Indeed, the likelihood ratio test showed that SLXNB models significantly outperformed the corresponding NB models at $p<0.001$. The likelihood ratio test also indicated that all SLXNB models, as well as their dispersion parameters, were significant at $p<0.001$. The better performance of the SLXNB models was expected since the Moran's I test (Table 6) showed that all mode share variables are spatially clustered in Victoria, with a high significance level of 0.001 (except for commuting by train with cycling access significant at $p<0.05)$. 

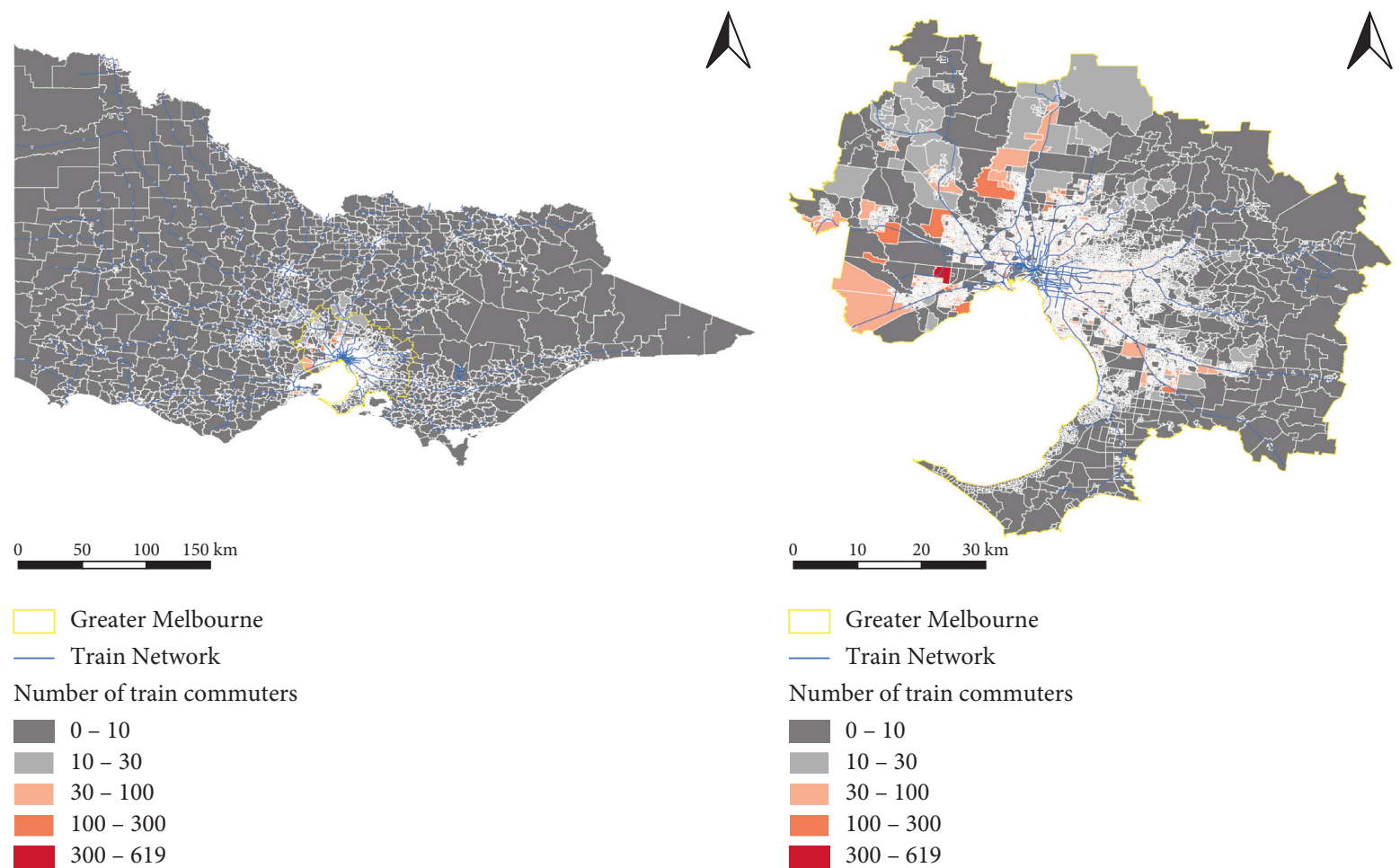

(a)

(b)

Figure 3: Number of train commuters at SA1 zones in 2016 (a) Whole of Victoria. (b) Greater Melbourne.

Table 1: Descriptive statistics at Statistical Area Level 1 (SA1)

\begin{tabular}{|c|c|c|c|c|c|c|c|c|c|}
\hline \multirow{2}{*}{ Variables } & \multirow{2}{*}{ Unit } & \multirow{2}{*}{$\begin{array}{l}\text { Victoria } \\
\text { Mean }\end{array}$} & \multicolumn{7}{|c|}{ Greater melbourne } \\
\hline & & & Std.Dev & Min & Max & Mean & Std.Dev & Min & $\operatorname{Max}$ \\
\hline Number of total crashes from 2014 to 2018 & Crashes & 4.511 & 8.188 & 0 & 345 & 4.386 & 8.431 & 0 & 345 \\
\hline Number of severe crashes from 2014 to 2018 & Crashes & 1.369 & 2.74 & 0 & 99 & 1.217 & 2.570 & 0 & 99 \\
\hline Population in 2016 & People & 429.872 & 193.294 & 3 & 4,354 & 445.863 & 199.802 & 3 & 4,354 \\
\hline Proportion of $0-14$ age group & $\%$ & 0.179 & 0.06 & 0 & 1 & 0.181 & 0.063 & 0 & 1 \\
\hline Proportion of unemployment & $\%$ & 0.066 & 0.043 & 0 & 0.549 & 0.068 & 0.042 & 0 & 0.549 \\
\hline Land use entropy & Index & 0.304 & 0.373 & 0 & 1 & 0.302 & 0.374 & 0 & 1 \\
\hline Proportion of freeway and arterial network & $\%$ & 0.208 & 0.222 & 0 & 1 & 0.224 & 0.239 & 0 & 1 \\
\hline Number of signalized intersections & Intersections & 0.245 & 0.84 & 0 & 33 & 0.280 & 0.877 & 0 & 33 \\
\hline Number of train stations & Stations & 0.023 & 0.156 & 0 & 2 & 0.024 & 0.163 & 0 & 2 \\
\hline Number of bus stops & Stops & 8.408 & 3.247 & 1 & 111 & 8.937 & 3.356 & 2 & 111 \\
\hline Number of tram stops & Stops & 0.118 & 0.56 & 0 & 16 & 0.162 & 0.650 & 0 & 16 \\
\hline Share of commuting by train with car access & $\%$ & 0.013 & 0.02 & 0 & 0.156 & 0.017 & 0.021 & 0 & 0.156 \\
\hline Share of commuting by train with walking access & $\%$ & 0.061 & 0.071 & 0 & 0.625 & 0.081 & 0.073 & 0 & 0.625 \\
\hline Share of commuting by train with feeder bus/tram & $\%$ & 0.014 & 0.023 & 0 & 0.301 & 0.018 & 0.025 & 0 & 0.301 \\
\hline Share of commuting by train with cycling access & $\%$ & 0.000 & 0.003 & 0 & 0.072 & 0.000 & 0.003 & 0 & 0.072 \\
\hline Share of commuting by bus & $\%$ & 0.012 & 0.025 & 0 & 0.292 & 0.014 & 0.027 & 0 & 0.292 \\
\hline Share of commuting by tram & $\%$ & 0.016 & 0.055 & 0 & 1 & 0.022 & 0.063 & 0 & 1 \\
\hline Share of commuting by walking & $\%$ & 0.037 & 0.065 & 0 & 1 & 0.030 & 0.061 & 0 & 1 \\
\hline Share of commuting by cycling & $\%$ & 0.011 & 0.027 & 0 & 0.455 & 0.013 & 0.030 & 0 & 0.455 \\
\hline Share of commuting by motorbike & $\%$ & 0.002 & 0.009 & 0 & 0.133 & 0.002 & 0.007 & 0 & 0.118 \\
\hline Share of commuting by car & $\%$ & 0.817 & 0.161 & 0 & 1 & 0.787 & 0.168 & 0 & 1 \\
\hline Total number of SA1 zones & Zones & & & 13,768 & & & 10,059 & & \\
\hline
\end{tabular}

Note: std. dev= standard deviation.

There were no multicollinearity issues. Table 7 showed that all variables in the SLXNB models had VIF values of less than 10 , a commonly adopted VIF threshold. This was also confirmed by Spearman and Pearson's correlation tests, where most correlation coefficients were below 0.8 (Figures 4 and 5). In addition to the total and severe crash SLXNB 
TABLE 2: Results of negative binomial regression for total crashes and severe crashes in Victoria

\begin{tabular}{|c|c|c|c|c|c|c|}
\hline \multirow{2}{*}{ Variables } & \multicolumn{3}{|c|}{ Total crashes } & \multicolumn{3}{|c|}{ Severe crashes } \\
\hline & Est. & SE & & Est. & SE & \\
\hline Intercept & -0.445 & 0.117 & $* * *$ & -1.087 & 0.146 & *** \\
\hline Log of population & 0.077 & 0.020 & $* * *$ & 0.061 & 0.025 & $*$ \\
\hline Proportion of $0--14$ age group & -1.631 & 0.184 & $* * *$ & -2.180 & 0.242 & *** \\
\hline Proportion of unemployment & -0.731 & 0.229 & $* *$ & -1.905 & 0.304 & $* * *$ \\
\hline Land use entropy & 0.039 & 0.026 & & -0.130 & 0.034 & *** \\
\hline Proportion of freeway and arterial network & 1.851 & 0.045 & $* * *$ & 1.662 & 0.057 & $* * *$ \\
\hline Number of signalized intersections & 0.261 & 0.012 & $* * *$ & 0.175 & 0.014 & $* * *$ \\
\hline Number of train stations & 0.200 & 0.058 & $* * *$ & 0.238 & 0.071 & $* * *$ \\
\hline Number of bus stops & 0.133 & 0.003 & $* * *$ & 0.130 & 0.004 & *** \\
\hline Number of tram stops & 0.098 & 0.018 & $* * *$ & 0.101 & 0.022 & $* * *$ \\
\hline Share of commuting by train with car access & -5.559 & 0.537 & $* * *$ & -6.594 & 0.724 & $* * *$ \\
\hline Share of commuting by train with walking access & -1.663 & 0.157 & $* * *$ & -2.356 & 0.209 & *** \\
\hline Share of commuting by train with feeder bus/tram & -0.894 & 0.491 & + & -1.864 & 0.656 & ** \\
\hline Share of commuting by train with cycling access & -1.416 & 3.427 & & -2.479 & 4.644 & \\
\hline Share of commuting by bus & -2.939 & 0.405 & $* * *$ & -3.875 & 0.539 & $* * *$ \\
\hline Share of commuting by tram & -2.021 & 0.240 & $* * *$ & -2.856 & 0.311 & *** \\
\hline Share of commuting by walking & 2.988 & 0.156 & $* * *$ & 3.204 & 0.190 & *** \\
\hline Share of commuting by cycling & 0.801 & 0.428 & + & -0.668 & 0.568 & \\
\hline Share of commuting by motorbike & 7.906 & 1.067 & $* * *$ & 9.453 & 1.313 & $* * *$ \\
\hline Dispersion parameter $(\theta)$ & 1.126 & 0.020 & $* * *$ & 0.912 & 0.023 & $* * *$ \\
\hline Log-likelihood & & $-31,942$ & & & $-19,720$ & \\
\hline AIC & & 63,924 & & & 39,480 & \\
\hline Sample size & & 13,768 & & & 13,768 & \\
\hline
\end{tabular}

Note: $+p<0.1 ;{ }^{*} p<0.05 ;{ }^{* *} p<0.01 ;{ }^{* * *} p<0.001$. Est. $=$ Estimated; $\mathrm{SE}=$ Standard error; AIC $=$ Akaike information criterion.

TABLE 3: Results of negative binomial regression for total crashes and severe crashes in Greater Melbourne

\begin{tabular}{|c|c|c|c|c|c|c|}
\hline \multirow{2}{*}{ Variables } & \multicolumn{3}{|c|}{ Total crashes } & \multicolumn{3}{|c|}{ Severe crashes } \\
\hline & Est. & SE & & Est & SE & \\
\hline Intercept & -1.039 & 0.136 & $* * *$ & -1.926 & 0.168 & **** \\
\hline Log of population & 0.110 & 0.023 & $* * *$ & 0.127 & 0.029 & $* * *$ \\
\hline Proportion of $0--14$ age group & -0.900 & 0.208 & $* * *$ & -1.578 & 0.278 & *** \\
\hline Proportion of unemployment & 0.027 & 0.270 & & -0.497 & 0.351 & \\
\hline Land use entropy & 0.216 & 0.030 & $* * *$ & 0.153 & 0.039 & $* * *$ \\
\hline Proportion of freeway and arterial network & 2.103 & 0.047 & $* * *$ & 1.935 & 0.060 & $* * *$ \\
\hline Number of signalized intersections & 0.317 & 0.013 & $* * *$ & 0.236 & 0.015 & $* * *$ \\
\hline Number of train stations & 0.223 & 0.062 & $* * *$ & 0.282 & 0.074 & $* * *$ \\
\hline Number of bus stops & 0.112 & 0.004 & $* * *$ & 0.103 & 0.004 & $* * *$ \\
\hline Number of tram stops & 0.074 & 0.018 & $* * *$ & 0.067 & 0.021 & $* *$ \\
\hline Share of commuting by train with car access & -2.581 & 0.568 & $* * *$ & -2.698 & 0.759 & $* * *$ \\
\hline Share of commuting by train with walking access & -0.486 & 0.170 & $* *$ & -1.051 & 0.221 & $* * *$ \\
\hline Share of commuting by train with feeder bus/tram & -0.045 & 0.482 & & -1.128 & 0.638 & + \\
\hline Share of commuting by train with cycling access & -1.467 & 3.495 & & -3.260 & 4.719 & \\
\hline Share of commuting by bus & -1.689 & 0.421 & $* * *$ & -2.444 & 0.555 & *** \\
\hline Share of commuting by tram & -0.976 & 0.254 & $* * *$ & -1.809 & 0.321 & $* * *$ \\
\hline Share of commuting by walking & 1.529 & 0.204 & $* * *$ & 1.515 & 0.244 & $* * *$ \\
\hline Share of commuting by cycling & 1.990 & 0.443 & $* * *$ & 1.150 & 0.574 & * \\
\hline Share of commuting by motorbike & 3.384 & 1.525 & $*$ & 2.444 & 1.969 & \\
\hline Dispersion parameter $(\theta)$ & 1.254 & 0.027 & $* * *$ & 1.136 & 0.039 & $* * *$ \\
\hline Log-likelihood & & $-22,465$ & & & $-13,286$ & \\
\hline AIC & & 44,970 & & & 26,611 & \\
\hline Sample size & & 10,059 & & & 10,059 & \\
\hline
\end{tabular}

Note: $+p<0.1 ;{ }^{*} p<0.05 ;{ }^{* *} p<0.01 ;{ }^{* * *} p<0.001$.Est. = Estimated; SE = Standard error; AIC $=$ Akaike information criterion. 
TABLE 4: Results of SLXNB model for total crashes and severe crashes in Victoria.

\begin{tabular}{|c|c|c|c|c|c|c|}
\hline \multirow{2}{*}{ Variables } & \multicolumn{3}{|c|}{ Total crashes } & \multicolumn{3}{|c|}{ Severe crashes } \\
\hline & Est. & SE & & Est. & SE & \\
\hline Intercept & -0.562 & 0.118 & $* * *$ & -1.178 & 0.147 & $* * *$ \\
\hline Log of population & 0.081 & 0.020 & $* * *$ & 0.061 & 0.025 & $*$ \\
\hline Proportion of $0-14$ age group & -1.391 & 0.184 & $* * *$ & -1.972 & 0.243 & $* * *$ \\
\hline Proportion of unemployment & -0.578 & 0.228 & $*$ & -1.654 & 0.301 & $* * *$ \\
\hline Land use entropy & 0.035 & 0.026 & & -0.125 & 0.034 & $* * *$ \\
\hline Proportion of freeway and arterial network & 1.855 & 0.045 & $* * *$ & 1.665 & 0.057 & $* * *$ \\
\hline Number of signalized intersections & 0.269 & 0.012 & $* * *$ & 0.179 & 0.014 & $* * *$ \\
\hline Number of train stations & 0.139 & 0.057 & $*$ & 0.156 & 0.070 & $*$ \\
\hline Number of bus stops & 0.141 & 0.003 & $* * *$ & 0.139 & 0.004 & $* * *$ \\
\hline Number of tram stops & 0.095 & 0.018 & $* * *$ & 0.101 & 0.022 & $* * *$ \\
\hline \multicolumn{7}{|l|}{ Direct effects of mode share variables } \\
\hline Share of commuting by train with car access & -1.812 & 0.589 & $* *$ & -1.980 & 0.792 & $*$ \\
\hline Share of commuting by train with walking access & -0.330 & 0.308 & & -0.305 & 0.405 & \\
\hline Share of commuting by train with feeder bus/tram & 0.451 & 0.559 & & 0.397 & 0.746 & \\
\hline Share of commuting by train with cycling access & -0.673 & 3.421 & & -0.947 & 4.645 & \\
\hline Share of commuting by bus & -0.629 & 0.569 & & -0.613 & 0.749 & \\
\hline Share of commuting by tram & -0.492 & 0.450 & & -0.701 & 0.562 & \\
\hline Share of commuting by walking & 1.075 & 0.214 & $* * *$ & 0.952 & 0.260 & $* * *$ \\
\hline Share of commuting by cycling & -0.513 & 0.627 & & -0.565 & 0.826 & \\
\hline Share of commuting by motorbike & 4.780 & 1.086 & $* * *$ & 5.490 & 1.341 & $* * *$ \\
\hline \multicolumn{7}{|l|}{ Indirect effects of mode share variables } \\
\hline Share of commuting by train with car access & -9.777 & 0.965 & $* * *$ & -11.700 & 1.300 & $* * *$ \\
\hline Share of commuting by train with walking access & -1.325 & 0.369 & $* * *$ & -1.923 & 0.488 & $* * *$ \\
\hline Share of commuting by train with feeder bus/tram & -1.135 & 0.920 & & -3.142 & 1.244 & $*$ \\
\hline Share of commuting by train with cycling access & -22.42 & 7.675 & $* *$ & -8.498 & 10.21 & \\
\hline Share of commuting by bus & -3.721 & 0.730 & $* * *$ & -4.972 & 0.972 & $* * *$ \\
\hline Share of commuting by tram & -2.880 & 0.507 & $* * *$ & -3.383 & 0.642 & $* * *$ \\
\hline Share of commuting by walking & 2.806 & 0.283 & $* * *$ & 3.213 & 0.349 & $* * *$ \\
\hline Share of commuting by cycling & 2.843 & 0.817 & $* * *$ & 0.391 & 1.075 & \\
\hline Share of commuting by motorbike & 14.227 & 2.093 & $* * *$ & 17.764 & 2.572 & $* * *$ \\
\hline Dispersion parameter $(\theta)$ & 1.175 & 0.021 & $* * *$ & 0.975 & 0.025 & $* * *$ \\
\hline Log-likelihood & $-31,751$ & $-19,550$ & & & & \\
\hline AIC & 63,561 & 39,158 & & & & \\
\hline Sample size & 13,768 & 13,768 & & & & \\
\hline
\end{tabular}

models, minor crashes SLXNB models were also considered (Tables 8 and 9). In general, the effects of mode share variables on minor crashes are similar to those on total crashes.

Since the SLXNB models have a better fit than the NB models, the following sections are based on the outcomes of the SLXNB models. The results of the total and severe crash SLXNB models in Victoria and Greater Melbourne are presented in Table 4 and 5, respectively, where the direct and indirect effects of commuting mode shares were estimated. The total effects of commuting mode shares are reported in Tables 10 and 11 for Victoria and Greater Melbourne, respectively.

4.1. SLXNB Model for Total Crashes and Severe Crashes in Victoria. As shown in Tables 4 and 10, while the proportion of commuting by train with FLM active transport and feeder bus/tram access direct effects was statistically insignificant, some of their indirect effects and total effects were significant. A rise in the proportion of train commuting with FLM walking access in Victoria was correlated with fewer total and severe crashes at a high significance level, considering indirect and total effects. The indirect and total safety effects of train commuting with FLM cycling access were negatively related and statistically significant in the total crashes SLXNB model in Victoria. Commuting by train with feeder bus or tram might correlate with a decrease of severe crashes in Victoria when taking its indirect effect and total effect into account. Only the coefficient of the proportion of train commuting with car access was negative and significant for all effects in both SLXNB models.

There was a lack of strong evidence of the bus and tram mode share's direct safety benefit. However, the share of commuting by bus and tram's indirect effects and total effects were negatively correlated with the total and severe crashes in Victoria's SLXNB models at $p<0.001$. The direct effects of the proportion of cycling to work were insignificant in both models. However, its indirect effect and total effect were significant and positively correlated with total crashes in the total crash model. Both total crashes and severe crashes tended to rise with increasing walking and motorcycling to work. 
TABLE 5: Results of SLXNB model for total crashes and severe crashes in Greater Melbourne.

\begin{tabular}{|c|c|c|c|c|c|c|}
\hline \multirow{2}{*}{ Variables } & \multicolumn{3}{|c|}{ Total crashes } & \multicolumn{3}{|c|}{ Severe crashes } \\
\hline & Est. & SE & & Est. & SE & \\
\hline Intercept & -0.976 & 0.140 & $* * *$ & -1.767 & 0.174 & *** \\
\hline Log of population & 0.110 & 0.023 & $* * *$ & 0.115 & 0.029 & $* * *$ \\
\hline Proportion of $0--14$ age group & -0.858 & 0.209 & $* * *$ & -1.556 & 0.279 & $* * *$ \\
\hline Proportion of unemployment & -0.012 & 0.271 & & -0.508 & 0.354 & \\
\hline Land use entropy & 0.207 & 0.030 & $* * *$ & 0.146 & 0.039 & $* * *$ \\
\hline Proportion of freeway and arterial network & 2.089 & 0.047 & $* * *$ & 1.918 & 0.060 & $* * *$ \\
\hline Number of signalized intersections & 0.318 & 0.013 & $* * *$ & 0.234 & 0.015 & $* * *$ \\
\hline Number of train stations & 0.203 & 0.062 & $* *$ & 0.246 & 0.074 & $* * *$ \\
\hline Number of bus stops & 0.113 & 0.004 & $* * *$ & 0.104 & 0.004 & $* * *$ \\
\hline Number of tram stops & 0.074 & 0.018 & $* * *$ & 0.076 & 0.021 & *** \\
\hline \multicolumn{7}{|l|}{ Direct effects of mode share variables } \\
\hline Share of commuting by train with car access & -1.783 & 0.606 & $* *$ & -1.797 & 0.809 & * \\
\hline Share of commuting by train with walking access & -0.340 & 0.311 & & -0.359 & 0.405 & \\
\hline Share of commuting by train with feeder bus/tram & 0.257 & 0.551 & & -0.001 & 0.727 & \\
\hline Share of commuting by train with cycling access & -1.262 & 3.506 & & -2.467 & 4.738 & \\
\hline Share of commuting by bus & -0.694 & 0.615 & & -1.003 & 0.803 & \\
\hline Share of commuting by tram & -0.562 & 0.442 & & -0.819 & 0.543 & \\
\hline Share of commuting by walking & 0.881 & 0.306 & $* *$ & 0.730 & 0.368 & * \\
\hline Share of commuting by cycling & 0.453 & 0.706 & & 0.998 & 0.916 & \\
\hline Share of commuting by motorbike & 3.277 & 1.528 & * & 2.710 & 1.972 & \\
\hline \multicolumn{7}{|l|}{ Indirect effects of mode share variables } \\
\hline Share of commuting by train with car access & -3.866 & 1.058 & $* * *$ & -4.179 & 1.413 & ** \\
\hline Share of commuting by train with walking access & -0.403 & 0.379 & & -0.957 & 0.496 & + \\
\hline Share of commuting by train with feeder bus/tram & -0.114 & 0.909 & & -2.217 & 1.217 & + \\
\hline Share of commuting by train with cycling access & -23.356 & 8.095 & $* *$ & -12.562 & 10.726 & \\
\hline Share of commuting by bus & -2.038 & 0.782 & $* *$ & -2.600 & 1.029 & $*$ \\
\hline Share of commuting by tram & -1.585 & 0.522 & $* *$ & -2.240 & 0.654 & $* * *$ \\
\hline Share of commuting by walking & 1.395 & 0.377 & $* * *$ & 1.752 & 0.461 & $* * *$ \\
\hline Share of commuting by cycling & 3.383 & 0.898 & $* * *$ & 1.626 & 1.167 & \\
\hline Share of commuting by motorbike & -1.936 & 3.605 & & -3.477 & 4.754 & \\
\hline Dispersion parameter $(\theta)$ & 1.265 & 0.027 & $* * *$ & 1.151 & 0.039 & $* * *$ \\
\hline Log-likelihood & & $-22,437$ & & & $-13,261$ & \\
\hline AIC & & 44,932 & & & 26,581 & \\
\hline Sample size & & 10,059 & & & 10,059 & \\
\hline
\end{tabular}

Note. $+p<0.1 ;{ }^{*} p<0.05 ;{ }^{* *} p<0.01 ;{ }^{* * *} p<0.001$. Est. $=$ estimated; $\mathrm{SE}=$ standard error; AIC $=$ Akaike information criterion.

TABle 6: Moran's I test statistics (Victoria)

\begin{tabular}{lcc}
\hline Variables & Moran's I & Z-Score \\
\hline Share of commuting by train with car access & 0.176 & 34.180 \\
Share of commuting by train with walking access & 0.902 & 175.498 \\
Share of commuting by train with feeder bus/tram & 0.397 & 77.260 \\
Share of commuting by train with cycling access & 0.009 & $1.712^{* * *}$ \\
Share of commuting by bus & 0.068 & 13.169 \\
Share of commuting by tram & 0.071 & $13.811^{* * *}$ \\
Share of commuting by walking & 0.079 & 15.451 \\
Share of commuting by cycling & 0.071 & 13.831 \\
Share of commuting by motorbike & 0.052 & 10.154 \\
\hline
\end{tabular}

Note: ${ }^{*} p<0.05 ;{ }^{* * *} p<0.001$.

The log of the population was positively associated with the total crashes and severe crashes, as expected. The percentage of the $0-14$ age group and the proportion of unemployment were negatively related to the crashes. In addition, the proportion of the freeway and arterial network, number of signalized intersections, amount of train stations, amount of bus stops, and amount of tram stops were all positively related to the total crashes and severe crashes at a high significance level. The land use entropy variable showed a negative relationship with severe crashes. 
TABLE 7: VIF values for explanatory variables in SLXNB models.

\begin{tabular}{|c|c|c|c|c|}
\hline \multirow{2}{*}{ Variables } & \multicolumn{2}{|c|}{ Victoria } & \multicolumn{2}{|c|}{ Greater melbourne } \\
\hline & Total crash & Severe crash & Total crash & Severe crash \\
\hline Log of population & 1.204 & 1.246 & 1.195 & 1.249 \\
\hline Proportion of $0-14$ age group & 1.384 & 1.414 & 1.475 & 1.532 \\
\hline Proportion of unemployment & 1.126 & 1.146 & 1.156 & 1.182 \\
\hline Land use mix - entropy & 1.078 & 1.086 & 1.087 & 1.088 \\
\hline Proportion of freeway and arterial network & 1.206 & 1.212 & 1.205 & 1.202 \\
\hline Number of signalized intersections & 1.407 & 1.461 & 1.513 & 1.609 \\
\hline Number of train stations & 1.092 & 1.102 & 1.11 & 1.126 \\
\hline Number of bus stops & 1.367 & 1.409 & 1.445 & 1.525 \\
\hline Number of tram stops & 1.524 & 1.549 & 1.524 & 1.553 \\
\hline \multicolumn{5}{|l|}{ Direct effects of mode share variables } \\
\hline Share of commuting by train with car access & 1.39 & 1.388 & 1.284 & 1.285 \\
\hline Share of commuting by train with walking access & 5.66 & 5.683 & 4.664 & 4.689 \\
\hline Share of commuting by train with feeder bus/tram & 1.917 & 1.956 & 1.687 & 1.707 \\
\hline Share of commuting by train with cycling access & 1.047 & 1.047 & 1.047 & 1.049 \\
\hline Share of commuting by bus & 2.192 & 2.159 & 2.352 & 2.316 \\
\hline Share of commuting by tram & 7.875 & 7.519 & 7.693 & 7.383 \\
\hline Share of commuting by walking & 2.604 & 2.619 & 3.712 & 3.792 \\
\hline Share of commuting by cycling & 3.463 & 3.336 & 4.238 & 4.183 \\
\hline Share of commuting by motorbike & 1.089 & 1.1 & 1.058 & 1.058 \\
\hline \multicolumn{5}{|l|}{ Indirect effects of mode share variables } \\
\hline Share of commuting by train with car access & 1.634 & 1.642 & 1.485 & 1.491 \\
\hline Share of commuting by train with walking access & 6.414 & 6.504 & 5.119 & 5.152 \\
\hline Share of commuting by train with feeder bus/tram & 2.83 & 2.94 & 2.213 & 2.274 \\
\hline Share of commuting by train with cycling access & 1.201 & 1.203 & 1.216 & 1.224 \\
\hline Share of commuting by bus & 2.249 & 2.215 & 2.421 & 2.374 \\
\hline Share of commuting by tram & 8.786 & 8.505 & 9.4 & 9.214 \\
\hline Share of commuting by walking & 3.05 & 3.118 & 4.348 & 4.532 \\
\hline Share of commuting by cycling & 4.482 & 4.297 & 5.455 & 5.376 \\
\hline Share of commuting by motorbike & 1.155 & 1.164 & 1.266 & 1.272 \\
\hline
\end{tabular}

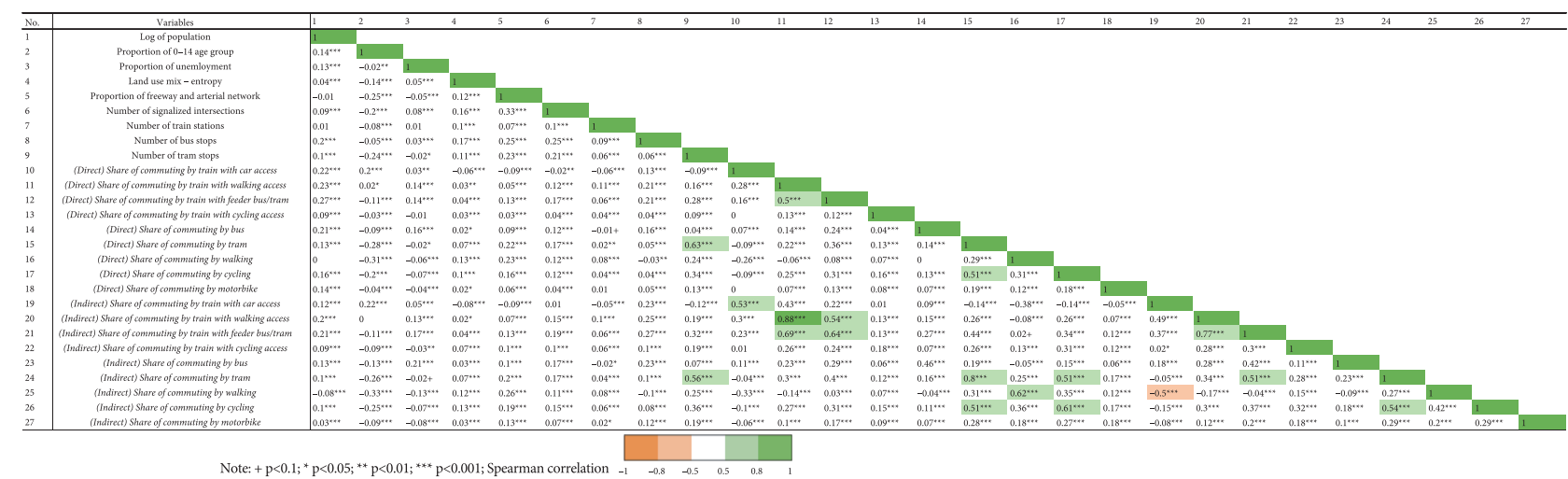

Figure 4: Spearman's rank correlation coefficients among explanatory variables (Victoria data) Note: $+p<0.1 ;{ }^{*} p<0.05$; ${ }^{* *} p<0.01$; *** $p<0.001$; Spearman correlation.

4.2. SLXNB Model for Total Crashes and Severe Crashes in Greater Melbourne. Two SLXNB models for the total crashes and severe crashes were developed for the Greater Melbourne area. As shown in Tables 5 and 11, all effects (direct, indirect, and total) of the share of commuting by train with car access showed a negative relationship with both crash types at a high significant level. In terms of walking access to train, the indirect safety benefit in the severe crash model was only marginally significant, while the direct effects and indirect effect on the total crashes were insignificant. However, its total effects were negatively and significantly associated with crashes in both SLXNB models. For the proportion of commuting by train with cycling access, its indirect and total effects were negatively related and significant in total crashes SLXNB models, while insignificant in the severe crashes SLXNB models. The direct effects of train commuting with cycling access were insignificant in both models. Additionally, the indirect effect and 


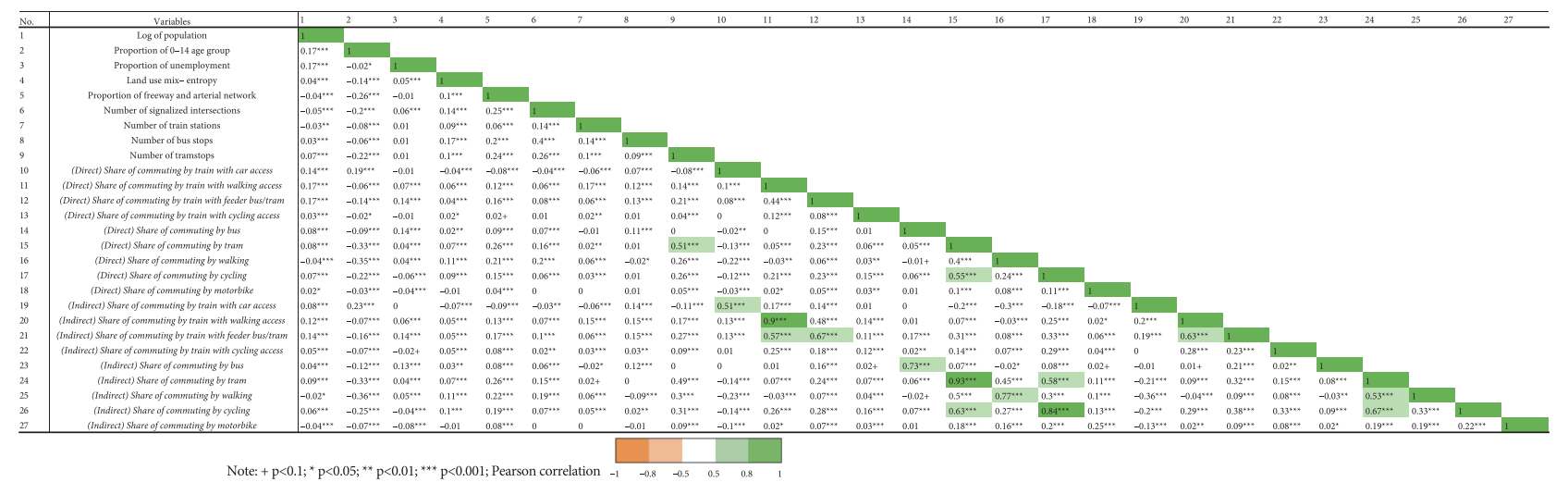

Figure 5: Pearson's correlation coefficients among explanatory variables (Victoria data) Note: $+p<0.1 ;{ }^{*} p<0.05 ;{ }^{* *} p<0.01{ }^{* * * *} p<0.001$; Pearson correlation.

TABLE 8: Results of SLXNB models for minor crashes.

\begin{tabular}{|c|c|c|c|c|c|c|}
\hline \multirow{2}{*}{ Variables } & \multicolumn{3}{|c|}{ Victoria } & \multicolumn{3}{|c|}{ Greater Melbourne } \\
\hline & Est. & SE & & Est. & SE & \\
\hline Intercept & -1.112 & 0.123 & $* * *$ & -1.421 & 0.147 & *** \\
\hline Log of population & 0.096 & 0.021 & $* * *$ & 0.112 & 0.024 & $* * *$ \\
\hline Proportion of $0-14$ age group & -1.186 & 0.194 & $* * *$ & -0.666 & 0.222 & $* *$ \\
\hline Proportion of unemployment & -0.156 & 0.238 & & 0.103 & 0.287 & \\
\hline Land use mix - entropy & 0.111 & 0.027 & $* * *$ & 0.240 & 0.032 & $* * *$ \\
\hline Proportion of freeway and arterial network & 1.821 & 0.046 & $* * *$ & 2.033 & 0.05 & $* * *$ \\
\hline Number of signalized intersections & 0.295 & 0.012 & $* * *$ & 0.335 & 0.013 & $* * *$ \\
\hline Number of train stations & 0.116 & 0.059 & $*$ & 0.162 & 0.065 & $*$ \\
\hline Number of bus stops & 0.136 & 0.003 & $* * *$ & 0.113 & 0.004 & $* * *$ \\
\hline Number of tram stops & 0.087 & 0.019 & $* * *$ & 0.070 & 0.018 & $* * *$ \\
\hline \multicolumn{7}{|l|}{ Direct effects of mode share variables } \\
\hline Share of commuting by train with car access & -1.769 & 0.624 & $* *$ & -1.809 & 0.649 & $* *$ \\
\hline Share of commuting by train with walking access & -0.299 & 0.321 & & -0.308 & 0.328 & \\
\hline Share of commuting by train with feeder bus/tram & 0.375 & 0.583 & & 0.250 & 0.582 & \\
\hline Share of commuting by train with cycling access & -0.690 & 3.573 & & -0.653 & 3.691 & \\
\hline Share of commuting by bus & -0.648 & 0.597 & & -0.611 & 0.652 & \\
\hline Share of commuting by tram & -0.572 & 0.459 & & -0.597 & 0.457 & \\
\hline Share of commuting by walking & 1.032 & 0.222 & $* * *$ & 0.842 & 0.319 & $* *$ \\
\hline Share of commuting by cycling & -0.545 & 0.652 & & 0.132 & 0.741 & \\
\hline Share of commuting by motorbike & 4.098 & 1.135 & $* * *$ & 3.295 & 1.607 & $*$ \\
\hline \multicolumn{7}{|l|}{ Indirect effects of mode share variables } \\
\hline Share of commuting by train with car access & -8.919 & 1.022 & $* * *$ & -3.725 & 1.133 & $* *$ \\
\hline Share of commuting by train with walking access & -0.976 & 0.385 & $*$ & -0.143 & 0.401 & \\
\hline Share of commuting by train with feeder bus/tram & -0.106 & 0.959 & & 0.915 & 0.96 & \\
\hline Share of commuting by train with cycling access & -29.047 & 8.136 & $* * *$ & -28.625 & 8.629 & $* * *$ \\
\hline Share of commuting by bus & -3.055 & 0.767 & $* * *$ & -1.762 & 0.83 & $*$ \\
\hline Share of commuting by tram & -2.302 & 0.518 & $* * *$ & -1.052 & 0.54 & + \\
\hline Share of commuting by walking & 2.389 & 0.294 & $* * *$ & 1.173 & 0.394 & $* *$ \\
\hline Share of commuting by cycling & 3.691 & 0.845 & $* * *$ & 3.895 & 0.939 & $* * *$ \\
\hline Share of commuting by motorbike & 11.708 & 2.197 & $* * *$ & -1.119 & 3.811 & \\
\hline Dispersion parameter $(\theta)$ & 1.195 & 0.024 & $* * *$ & 1.244 & 0.03 & $* * *$ \\
\hline Log-likelihood & $-27,499$ & $-19,693$ & & & & \\
\hline AIC & 55,055 & 39,443 & & & & \\
\hline Sample size & 13,768 & 10,059 & & & & \\
\hline
\end{tabular}

Note: ${ }^{+} p<0.1 ;{ }^{*} p<0.05 ;{ }^{* *} p<0.01 ;{ }^{* * *} p<0.001$, Est. = Estimated; SE = Standard error; AIC = Akaike information criterion.

total effect of commuting by train with feeder bus/tram appeared to be positively associated with road safety improvement at a marginal significance level in the severe crash model, but its other effects were not statistically significant.
With respect to other main commuting modes, the direct effects of other transit modes (bus and tram) were insignificant. However, their indirect effects and total effects were significantly and negatively associated with both crash types. The 
TABLE 9: Total effects of mode share variables on minor crashes.

\begin{tabular}{|c|c|c|c|c|c|c|}
\hline \multirow{2}{*}{ Variables } & \multicolumn{3}{|c|}{ Victoria } & \multicolumn{3}{|c|}{ Greater Melbourne } \\
\hline & Est. & SE & & Est. & SE & \\
\hline Share of commuting by train with car access & -10.688 & 1.077 & $* * *$ & -5.535 & 1.258 & $* * *$ \\
\hline Share of commuting by train with walking access & -1.275 & 0.212 & $* * *$ & -0.452 & 0.245 & + \\
\hline Share of commuting by train with feeder bus/tram & 0.269 & 0.835 & & 1.165 & 0.842 & \\
\hline Share of commuting by train with cycling access & -29.737 & 9.044 & $* *$ & -29.278 & 10.091 & $* *$ \\
\hline Share of commuting by bus & -3.703 & 0.619 & $* * *$ & -2.373 & 0.651 & $* * *$ \\
\hline Share of commuting by tram & -2.874 & 0.292 & $* * *$ & -1.649 & 0.343 & $* * *$ \\
\hline Share of commuting by walking & 3.421 & 0.24 & $* * *$ & 2.015 & 0.279 & $* * *$ \\
\hline Share of commuting by cycling & 3.146 & 0.614 & $* * *$ & 4.026 & 0.649 & $* * *$ \\
\hline Share of commuting by motorbike & 15.806 & 2.368 & $* * *$ & 2.177 & 4.485 & \\
\hline
\end{tabular}

Note: ${ }^{+} p<0.1 ;{ }^{* *} p<0.01 ;{ }^{* * *} p<0.001$, Est. = Estimated; SE = Standard error; AIC = Akaike information criterion.

Table 10: Total effects of mode share variables on total crashes and severe crashes in Victoria.

\begin{tabular}{|c|c|c|c|c|c|c|}
\hline \multirow{2}{*}{ Variables } & \multicolumn{3}{|c|}{ Total crashes } & \multicolumn{3}{|c|}{ Severe crashes } \\
\hline & Est. & SE & & Est. & SE & \\
\hline Share of commuting by train with car access & -11.588 & 1.063 & *** & -13.680 & 1.382 & $* * *$ \\
\hline Share of commuting by train with walking access & -1.655 & 0.204 & $* * *$ & -2.228 & 0.265 & $* * *$ \\
\hline Share of commuting by train with feeder bus/tram & -0.684 & 0.816 & & -2.745 & 1.092 & $*$ \\
\hline Share of commuting by train with cycling access & -23.098 & 8.551 & $* *$ & -9.444 & 10.616 & \\
\hline Share of commuting by bus & -4.349 & 0.580 & $* * *$ & -5.585 & 0.656 & $* * *$ \\
\hline Share of commuting by tram & -3.372 & 0.287 & $* * *$ & -4.083 & 0.374 & $* * *$ \\
\hline Share of commuting by walking & 3.881 & 0.232 & $* * *$ & 4.165 & 0.260 & *** \\
\hline Share of commuting by cycling & 2.330 & 0.607 & $* * *$ & -0.174 & 0.794 & \\
\hline Share of commuting by motorbike & 19.006 & 2.312 & $* * *$ & 23.254 & 2.616 & *** \\
\hline
\end{tabular}

Note: ${ }^{*} p<0.05 ;{ }^{* *} p<0.01 ;{ }^{* * *} p<0.001$; Est. = Estimated; SE = Standard error.

TABLE 11: Total effects of mode share variables on total crashes and severe crashes in Greater Melbourne.

\begin{tabular}{|c|c|c|c|c|c|c|}
\hline \multirow{2}{*}{ Variables } & \multicolumn{3}{|c|}{ Total crashes } & \multicolumn{3}{|c|}{ Severe crashes } \\
\hline & Est. & SE & & Est. & SE & \\
\hline Share of commuting by train with car access & -5.649 & 1.254 & *** & -5.976 & 1.609 & $* * *$ \\
\hline Share of commuting by train with walking access & -0.742 & 0.240 & $* *$ & -1.316 & 0.312 & $* * *$ \\
\hline Share of commuting by train with feeder bus/tram & 0.143 & 0.829 & & -2.218 & 1.138 & + \\
\hline Share of commuting by train with cycling access & -24.62 & 9.849 & * & -15.03 & 12.505 & \\
\hline Share of commuting by bus & -2.732 & 0.606 & *** & -3.603 & 0.707 & *** \\
\hline Share of commuting by tram & -2.147 & 0.343 & $* * *$ & -3.059 & 0.457 & $* * *$ \\
\hline Share of commuting by walking & 2.276 & 0.287 & $* * *$ & 2.482 & 0.340 & $* * *$ \\
\hline Share of commuting by cycling & 3.837 & 0.633 & $* * *$ & 2.623 & 0.808 & ** \\
\hline Share of commuting by motorbike & 1.341 & 4.523 & & -0.768 & 5.963 & \\
\hline
\end{tabular}

Note: $+p<0.1 ;{ }^{*} p<0.05 ;{ }^{* *} p<0.01 ;{ }^{* * *} p<0.001$. Est. $=$ estimated; $\mathrm{SE}=$ standard error.

proportion of commuting by walking had significantly positive coefficients for all effects. The total effects on the two crash types and indirect effects on total crashes of commuting by cycling were positively related and significant, while its other effects were insignificant. The percentage of motorbike commuters was only positively correlated with total crashes when considering the direct effect. Other safety impacts of the share of motorbike commuting were insignificant. In addition to the commuting modes, the study found that the effects of land use entropy were positively correlated with both total crashes and severe crashes at a high significance level. However, the proportion of unemployment was insignificant. Other results in the SLXNB models for Greater Melbourne were similar to those of the Victoria SLXNB models (Table 4).

\section{Discussion and Conclusion}

Interpretations were made using incidence rate ratios (i.e., exponents of model coefficients) and marginal effects. Using the incidence rate ratios, the percentage change in the number of crashes in response to an increase of an explanatory variable (e.g., one percentage point) can be calculated. The $\mathrm{mfx}$ package in $\mathrm{R}$ [71] was used to calculate the marginal effects of the mean value of observations (showing 
the change in the number of crashes per zone, on average, in response to an increase of an explanatory variable).

The results confirmed that a higher share of commuters using public transport was correlated with fewer crashes (both crash types). Particularly, a percentage point growth in the percentage of train commuters with car access would be related to a decrease of total crashes by 10.94 per cent and severe crashes by 12.79 per cent in Victoria (or 0.36 total crashes and 0.13 severe crashes per zone according to the marginal effect). The mode shifting from car to train with car access tended to relate to a smaller safety effect in Greater Melbourne than in the whole of Victoria, at 5.49 per cent and 5.8 per cent reduction for total crashes and severe crashes, for each one percentage point increase (equivalent to 0.16 and 0.05 crashes per zone, respectively). The reason may be that car travel in the whole of Victoria state had a higher risk than in Greater Melbourne due to the higher risks associated with longer distances and rural/ regional travel. Therefore, a modal shift from driving to riding a train with car access in Victoria would reduce more crash exposure and crash likelihood, thus, might have a higher impact on road safety than in Greater Melbourne.

The results on the safety impacts of commuting by train with feeder bus/tram indicated that a percentage point rise in the share of this mode might be associated with a reduction of severe crashes in Victoria by 2.71 per cent $(0.03$ crashes), and in Greater Melbourne by 2.19 per cent ( 0.02 crashes). One possible reason might be the speed of vehicle were reduced around bus/ tram stops [76]. There was no strong statistical evidence on the safety impact of commuting by train with feeder bus/tram in total crash models. Considering a multimodal trip of train commuting with feeder bus/tram access, the commuter might need to have an additional trip to connect bus/tram and train, compared to commuting by train, bus, or tram only. This additional trip would include some walking that might also add another risk, offsetting the safety benefit of commuting by train with feeder bus/tram.

In addition, a modal shift from commuting by car to commuting by train with FLM active mode (walking and cycling) access might have a negative relationship with crashes in both Victoria and Greater Melbourne. Particularly, when the share of train commuting with walking access grows a percentage point, road safety tends to improve by 1.64 per cent in total crashes ( 0.05 crashes) and 2.2 per cent in severe crashes (0.02 crashes) in Victoria. Similarly, a one percentage point rises in the share of rail commuters with walking access may be related to a decrease of 0.74 per cent in total crashes $(0.02$ crashes) and 1.31 per cent in severe crashes (0.01 crashes) in Greater Melbourne. Compared to car access and feeder bus/ tram, FLM walking access is associated with smaller safety effects. An explanation might be commuters were more likely to choose motorized access mode over nonmotorized access mode (such as walking) to connect to train stations as the length of commuting trips increased [77]. Therefore, a model shift from commuting by car to commuting by train with walking access might have less crash exposure reduction than to commuting by train with car access or feeder bus/tram.

Likewise, a percentage point growth in the share of train commuting with cycling access might correlate with significantly fewer the total crashes' number by 20.62 per cent $(0.72$ crashes) in Victoria and 21.82 per cent (0.7 crashes) in Greater Melbourne. However, the proportion of commuting by train with FLM cycling access was low at around $0.043 \%$ of all commuting modes. Therefore, a one percentage point increase will be a dramatic change for this access mode. These safety effects tended to be significantly better compared to other access modes.

A possible explanation for the positive safety benefits of commuting by train with FLM active transport access, given pedestrians and cyclists are vulnerable road users, is that train commuting tended to be a safe travel mode [2,3]. Moreover, the environment surrounding Victoria's train stations might be relatively friendly for active transport, especially cycling. Also, as the share of active access mode increased around train stations, the "safety in number" [38] might occur that drivers might be more aware of pedestrians and cyclists' safety. These findings suggested that promoting commuting by train with walking and cycling for FLM access likely provides traffic safety benefits at a network level in Victoria and Greater Melbourne, in addition to other benefits such as health, environment, and travel cost, which were found in the literature [22].

In terms of other public transport modes, commuting by bus might be associated with a more positive impact on traffic safety compared to trams. One percentage point rises in the share of bus commuters may be related to a drop of 4.26 per cent in total crashes ( 0.14 crashes) and 5.43 per cent in severe crashes (0.05 crashes) in Victoria. Tram transit also has a positive relationship with road safety, since a percentage point growth in the percentage of tram commuters is associated with a decrease of total crashes by 3.32 per cent $(0.11$ crashes $)$ and severe crashes by 4 per cent (0.04 crashes) in Victoria. Similar but smaller safety benefits in Greater Melbourne, compared to the whole of Victoria, could be found in relation to the share of bus commuting (2.7 per cent or 0.08 total crashes/3.54 per cent or 0.03 severe crashes) and tram commuting (2.12 per cent or 0.06 total crashes/3.01 per cent or 0.03 severe crashes). The modal shift from car to public transport for commuting seemed to relate to a relatively large safety benefit on severe crashes, as public transport is known to have lower fatality rates in comparison with other modes [78]. Besides, the relation to a higher safety effect of the bus in comparison with the tram could be partially explained by the operation of the tram as streetcars in a large proportion of the tram network in Melbourne [79]. Tram users may be exposed to high crash risk when access or egress to/from tram stops located on the road median. Moreover, the complex environment around the tram lines/ stops might increase the crash likelihood of surrounding vehicles.

Journeys to work by walking and cycling were mostly positively associated with the number of total crashes and severe crashes, except the journey to work by cycling was insignificant in the severe crash model for the whole of Victoria. Total crashes and severe crashes may decrease by 3.96 per cent $(0.12$ crashes) and 4.25 per cent (0.04 crashes), respectively, in relation to a percentage point increase of the proportion of commuting by walking in Victoria, whereas, in Greater Melbourne, a percentage point rise of commuting by walking might relate to a 2.3 per cent ( 0.07 crashes) rise in total crashes and a 2.51 per cent (0.02 crashes) rise in severe crashes. Regarding the effect of 
commuting by cycling, increasing a percentage point in its proportion might be related to a 2.36 per cent $(0.07$ crashes $)$ rise in total crashes in Victoria. The figures for additional crashes in Greater Melbourne were larger at 3.91 per cent of total crashes ( 0.11 crashes) and 2.66 per cent of severe crashes ( 0.02 crashes). A percentage point rise in the share of motorbike commuting might be associated with a significant rise of 20.93 per cent $(0.59$ crashes) in total crashes and 26.18 per cent $(0.23$ crashes) in severe crashes in Victoria. The relationship of the percentage of commuters using motorbikes in Greater Melbourne with crashes seemed to be insignificant. The above figures indicated that Victoria and Greater Melbourne might not provide enough safe environment for active transport modes and motorbikes, especially for cycling in the metropolitan areas and motorcycling in Victoria. Overall, the results were consistent with crash rates reported in Australia, which indicated motorcycling, walking, and cycling in Australia were more dangerous than driving [80]. Specifically, the fatality rate per 10 million kilometers traveled was $1.39,0.62,0.2$, and 0.04 for motorcycling, walking, cycling, and driving, respectively [80].

The effects of population, the proportion of the $0-14$ age group, and the proportion of unemployment variables were consistent with other studies [56-59]. Similarly, the positive correlations between crashes and the proportion of freeway and arterial network, or the number of train stations, bus stops, and tram stops, or the number of signalized intersections were in alignment with previous studies $[49,61,62]$. In terms of land use, a more mixed land use tended to be related to a rise in total and severe crashes in Greater Melbourne, but a safety improvement in severe crashes for the whole Victoria state. The highly mixed land use in urban areas might attract more population and active travel, hence increased crash exposure [58]. However, it might also shorten travel distances [31], thus reducing crash exposure. These two opposite effects might be the reason behind the mixed safety effect of land use entropy. Further research should be done to deeply understand the safety impact of mixed land use.

Overall, taking the network as a whole, modeling results show that train commuting tends to be associated with an improvement of network-wide road safety, regardless of FLM access modes (walking, cycling, car, or feeder bus/tram). An important implication from the findings is that promoting walking and cycling for FLM train access would create a synergistic effect on public health, the environment, the economy, and road safety. This is particularly true for promoting cycling as a train access mode, given its potential safety benefits and larger catchment size compared to walking. Policies that aim at improving walking and cycling infrastructure to connect to train stations (e.g., walking paths, bicycle lanes, or secured bicycle parking such as Parkiteer facilities in Victoria [81]) around train stations should be given more attention.

In addition, improving train feeder modes by bus and tram could lead to benefits (reduced severe crashes) beyond ridership. To this end, policies that aim at enhancing timetable coordination and feeder service coverage should be encouraged to attract more train users using bus/tram feeder access mode. From a theoretical perspective, the findings confirm the appropriateness of using macroscopic (network-level) safety modeling to capture the system-wide relationships between mode share variations and traffic safety. The correlations between crashes in a zone and travel mode shares in its neighboring zones have also been confirmed and quantified by the SLXNB models.

Given a substantial contribution to road safety at the network level, improving car access to train stations, especially in outer zones, should also be considered. Public transport is being promoted and its ridership is forecasted to grow in Victoria. However, if the share of train access by car is unchanged, and given the car parks at most stations have reached their capacity [81], the lack of car parks at train stations may become a significant issue. The lack of car parks may lead to overflow parking into neighboring streets, impacting residents, traffic flow, and safety. Thus, policies that aim at improving car access to train stations, such as the Victorian government's plan to provide over 11,000 new and upgraded car parking spaces for train commuters [82], would encourage park and ride activities and generate substantial road safety benefits.

Micromobility, e.g., e-scooters, has great potential to be an FLM train access alternative. Recently, e-scooter hire schemes have been trialed in Melbourne's inner councils. Since the ABS census data and household travel survey data currently do not capture information about e-scooter, it was not possible to investigate the potential safety effects of e-scooters as an FLM train access mode in this study. Future research should consider the safety effect of e-scooters as an FLM alternative.

Another limitation of this study is that mode share data were derived from a cross-sectional survey on only one census day. Using other travel survey data may help to address this issue. Moreover, future research should explore the application of other models such as the spatial Durbin model or spatial error model to capture the potential spatial correlation of collisions on the border of SA1 or other unobserved correlations. Random-parameter or bivariate modeling may also be worth consideration to address potential heterogeneity and interaction issues. In addition, more dependent variables and independent variables should be tested, such as public transport crashes, the number of casualties, or vehicle kilometers traveled to account for all traffics going through an area. Analyses can also be conducted with other spatial units, such as traffic analysis zones.

\section{Data Availability}

Data will be provided upon request.

\section{Conflicts of Interest}

The authors declare that there are no conflicts of interest.

\section{Authors' Contributions}

Duc C. Phan conceptualized the study, was responsible for methodology, data curation, and formal analysis, provided software, investigated and visualized the study, and wrote the original draft. Long T. Truong conceptualized the study, was responsible for methodology, investigated and supervised the study, and wrote the original draft. Hien D. Nguyen conceptualized and investigated the study, was responsible 
for methodology, and and reviewed and edited the manuscript. Richard Tay was responsible for methodology, investigated the study, and reviewed and edited the manuscript.

\section{Acknowledgments}

This research was supported by the Road Safety Innovation Fund. HDN was supported by ARC grant DP180101192.

\section{References}

[1] D. A. Hensher, "The imbalance between car and public transport use in urban Australia: why does it exist?" Transport Policy, vol. 5, no. 4, pp. 193-204, 1998.

[2] M. Moeinaddini, Z. Asadi-Shekari, Z. Sultan, and M. Zaly Shah, "Analyzing the relationships between the number of deaths in road accidents and the work travel mode choice at the city level," Safety Science, vol. 72, pp. 249-254, 2015.

[3] L. T. Truong and G. Currie, "Macroscopic road safety impacts of public transport: a case study of Melbourne, Australia," Accident Analysis \& Prevention, vol. 132, 2019.

[4] M. J. N. Keijer and P. Rietveld, "How do people get to the railway station? The Dutch experience," Transportation Planning and Technology, vol. 23, no. 3, pp. 215-235, 2000.

[5] R. Cervero, "Walk-and-ride: factors influencing pedestrian access to transit," Journal of Public Transportation, vol. 3, no. 4 , pp. 1-23, 2001.

[6] M. A. Replogle and H. Parcells, Linking Bicycle/Pedestrian Facilities with Transit, National Association of Railroad Passengers, 1992.

[7] D. S. Vale, "Transit-oriented development, integration of land use and transport, and pedestrian accessibility: combining node-place model with pedestrian shed ratio to evaluate and classify station areas in Lisbon," Journal of Transport Geography, vol. 45, pp. 70-80, 2015.

[8] D. Merriman, "How many parking spaces does it take to create one additional transit passenger?" Regional Science and Urban Economics, vol. 28, no. 5, pp. 565-584, 1998.

[9] J. L. Schank, "Encouraging kiss-and-ride at commuter railroad stations," Transportation Research Record: Journal of the Transportation Research Board, vol. 1793, no. 1, pp. 7-14, 2002.

[10] M. Shirgaokar and E. Deakin, "Study of park-and-ride facilities and their use in the san francisco bay area of California," Transportation Research Record: Journal of the Transportation Research Board, vol. 1927, no. 1, pp. 46-54, 2005.

[11] C. V. Zegeer and M. Bushell, "Pedestrian crash trends and potential countermeasures from around the world," Accident Analysis \& Prevention, vol. 44, no. 1, pp. 3-11, 2012.

[12] R. Cervero, B. Caldwell, and J. Cuellar, "Bike-and-ride: build it and they will come," Journal of Public Transportation, vol. 16, no. 4, p. 5, 2013.

[13] M. Replogle, "The role of bicycles in public transportation access," Transportation Research Record, vol. 959, pp. 55-62, 1984.

[14] Bureau of Infrastructure Transport and Regional Economics, "Australian road deaths database," in Bureau of Infrastructure Transport and Regional Economics, Canberra, Australia, 2021, https://www.bitre.gov.au/statistics/safety/ fatal_road_crash_database.

[15] City of Melbourne, Transport Strategy: Effective and Integrated Public Transport, Victoria, Melbourne, Australia, 2012, https://www.melbourne.vic.
gov.au/SiteCollectionDocuments/transport-strategy-201203-effective-integrated-public-transport.pdf.

[16] City of Melbourne, Walking Plan 2014-17, Victoria, Melbourne, Australia, 2014, https://www.melbourne.vic.gov.au/ parking-and-transport/streets-and-pedestrians/Pages/walkingplan-2014-17.aspx.

[17] City of Melbourne, Bicycle Plan 2016-2020, Victoria, Melbourne, Australia, 2016, https://www.melbourne.vic.gov.au/ parking-and-transport/cycling/Pages/bicycle-plan.aspx.

[18] Department of Transport, Pedestrian Access Strategy, A Strategy to Increase Walking for Transport in Victoria, Victoria, Australia: Department of Transport, Melbourne, Australia, 2010, https://www.victoriawalks.org.au/walking_strategies/.

[19] Department of Transport, Victorian Road Safety Action Plan 2021-2023, Victoria, Australia: Department of Transport, 2021, https://transport.vic.gov.au/getting-around/roads/safer-roadsin-our-hands.

[20] Australian Bureau of Statistics, Census of population and housing, Australian Bureau of Statistics, Canberra, Australia, 2016, https://www.abs.gov.au/statistics/microdata-tablebuilder/ tablebuilder.

[21] Australian Bureau of Statistics, TableBuilder, User Guide, Confidentiality, Australian Bureau of Statistics, Canberra, Australia, 2019.

[22] M. Wedderburn, Improving the Cost-Benefit Analysis of Integrated PT, Walking and Cycling, NZ Transport Agency, Wellington, New Zealand, 2013.

[23] C. Morency, M. Trépanier, and M. Demers, "Walking to transit: an unexpected source of physical activity," Transport Policy, vol. 18, no. 6, pp. 800-806, 2011.

[24] P. Topalovic, J. Carter, M. Topalovic, and G. Krantzberg, "Light rail transit in Hamilton: health, environmental and economic impact analysis," Social Indicators Research, vol. 108, no. 2, pp. 329-350, 2012.

[25] L. Besser and A. Dannenberg, "Walking to public TransitSteps to help meet physical activity recommendations," American Journal of Preventive Medicine, vol. 29, no. 4, pp. 273-280, 2005.

[26] K. Martens, "The bicycle as a feedering mode: experiences from three European countries," Transportation Research Part D: Transport and Environment, vol. 9, no. 4, pp. 281-294, 2004.

[27] S. L. Handy, M. G. Boarnet, R. Ewing, and R. E. Killingsworth, "How the built environment affects physical activity," American Journal of Preventive Medicine, vol. 23, no. 2, pp. 64-73, 2002.

[28] M. G. Boarnet, G. Giuliano, Y. Hou, and E. J. Shin, "First/last mile transit access as an equity planning issue," Transportation Research Part A: Policy and Practice, vol. 103, pp. 296-310, 2017.

[29] J. P. Pritchard, M. Stępniak, and K. T. Geurs, "Equity analysis of dynamic bike-and-ride accessibility in The Netherlands," in Measuring Transport Equity, pp. 73-83, Elsevier, Chennai, Tamil Nadu, 2019.

[30] L. Bouaoun, M. M. Haddak, and E. Amoros, "Road crash fatality rates in France: a comparison of road user types, taking account of travel practices," Accident Analysis \& Prevention, vol. 75, pp. 217-225, 2015.

[31] R. Amoh-Gyimah, M. Saberi, and M. Sarvi, "Macroscopic modeling of pedestrian and bicycle crashes: a cross-comparison of estimation methods," Accident Analysis \& Prevention, vol. 93, pp. 147-159, 2016.

[32] Q. Cai, J. Lee, N. Eluru, and M. Abdel-Aty, "Macro-level pedestrian and bicycle crash analysis: incorporating spatial spillover effects in dual state count models," Accident Analysis \& Prevention, vol. 93, pp. 14-22, 2016. 
[33] P. M. Hess, A. V. Moudon, and J. M. Matlick, "Pedestrian safety and transit corridors," Journal of Public Transportation, vol. 7, no. 2, p. 5, 2004.

[34] L. T. Truong and S. V. Somenahalli, "Using GIS to identify pedestrian-vehicle crash hot spots and unsafe bus stops," Journal of Public Transportation, vol. 14, no. 1, p. 6, 2011.

[35] S. Ukkusuri, L. F. Miranda-Moreno, G. Ramadurai, and J. IsaTavarez, "The role of built environment on pedestrian crash frequency," Safety Science, vol. 50, no. 4, pp. 1141-1151, 2012.

[36] R. Elvik and T. Bjørnskau, "Safety-in-numbers: a systematic review and meta-analysis of evidence," Safety Science, vol. 92, pp. 274-282, 2017.

[37] D. L. Robinson, "Safety in numbers in Australia: more walkers and bicyclists, safer walking and bicycling," Health Promotion Journal of Australia, vol. 16, no. 1, pp. 47-51, 2005.

[38] P. L. Jacobsen, "Safety in numbers: more walkers and bicyclists, safer walking and bicycling," Injury Prevention, vol. 21, no. 4, pp. 271-275, 2015.

[39] M. Brons, M. Givoni, and P. Rietveld, "Access to railway stations and its potential in increasing rail use," Transportation Research Part A: Policy and Practice, vol. 43, no. 2, pp. 136-149, 2009.

[40] C. Liu, S. Erdogan, T. Ma, and F. W. Ducca, "How to increase rail ridership in Maryland: direct ridership models for policy guidance," Journal of Urban Planning and Development, vol. 142, no. 4, 2016.

[41] Z.-j. Wang, F. Chen, and T.-k. Xu, "Interchange between metro and other modes: access distance and catchment area," Journal of Urban Planning and Development, vol. 142, no. 4, 2016.

[42] K. Halldórsdóttir, O. A. Nielsen, and C. G. Prato, "Home-end and activity-end preferences for access to and egress from train stations in the Copenhagen region," International Journal of Sustainable Transportation, vol. 11, no. 10, pp. 776-786, 2017.

[43] Y. Guo, L. Yang, W. Huang, and Y. Guo, "Traffic safety perception, attitude, and feeder mode choice of metro commute: evidence from Shenzhen," International Journal of Environmental Research and Public Health, vol. 17, no. 24, 2020.

[44] H. Huang, M. A. Abdel-Aty, and A. L. Darwiche, "Countylevel crash risk analysis in Florida: bayesian spatial modeling," Transportation Research Record: Journal of the Transportation Research Board, vol. 2148, no. 1, pp. 27-37, 2010.

[45] C. Siddiqui, M. Abdel-Aty, and K. Choi, "Macroscopic spatial analysis of pedestrian and bicycle crashes," Accident Analysis \& Prevention, vol. 45, pp. 382-391, 2012.

[46] L. T. Truong, L.-M. Kieu, and T. A. Vu, "Spatiotemporal and random parameter panel data models of traffic crash fatalities in Vietnam," Accident Analysis \& Prevention, vol. 94, pp. 153-161, 2016.

[47] M. Abdel-Aty, J. Lee, C. Siddiqui, and K. Choi, “Geographical unit based analysis in the context of transportation safety planning," Transportation Research Part A: Policy and Practice, vol. 49, pp. 62-75, 2013.

[48] Q. Cai, M. Abdel-Aty, J. Lee, and N. Eluru, "Comparative analysis of zonal systems for macro-level crash modeling," Journal of Safety Research, vol. 61, pp. 157-166, 2017.

[49] I. Tasic and R. J. Porter, "Modeling spatial relationships between multimodal transportation infrastructure and traffic safety outcomes in urban environments," Safety Science, vol. 82, pp. 325-337, 2016.

[50] H.-H. Ha and J.-C. Thill, "Analysis of traffic hazard intensity: a spatial epidemiology case study of urban pedestrians,"
Computers, Environment and Urban Systems, vol. 35, no. 3, pp. 230-240, 2011.

[51] N. Levine, K. E. Kim, and L. H. Nitz, "Spatial analysis of Honolulu motor vehicle crashes: II. Zonal generators," Accident Analysis \& Prevention, vol. 27, no. 5, pp. 675-685, 1995.

[52] M. Pljakić, D. Jovanović, B. Matović, and S. Mićić, "Macrolevel accident modeling in Novi Sad: a spatial regression approach," Accident Analysis \& Prevention, vol. 132, 2019.

[53] J. Lee, M. Abdel-Aty, K. Choi, and H. Huang, "Multi-level hot zone identification for pedestrian safety," Accident Analysis \& Prevention, vol. 76, pp. 64-73, 2015.

[54] M. A. Quddus, "Modelling area-wide count outcomes with spatial correlation and heterogeneity: an analysis of London crash data," Accident Analysis \& Prevention, vol. 40, no. 4, pp. 1486-1497, 2008.

[55] J. P. Elhorst, Spatial econometrics: from cross-sectional data to spatial panels, Vol. 479, Springer, NY, USA, 2014.

[56] M. G. Karlaftis and A. P. Tarko, "Heterogeneity considerations in accident modeling," Accident Analysis \& Prevention, vol. 30, no. 4, pp. 425-433, 1998.

[57] J. Lee and M. Abdel-Aty, "Macro-level analysis of bicycle safety: focusing on the characteristics of both crash location and residence," International journal of sustainable transportation, vol. 12, no. 8, pp. 553-560, 2018.

[58] K.-A. Rhee, J.-K. Kim, Y.-I. Lee, and G. F. Ulfarsson, "Spatial regression analysis of traffic crashes in Seoul," Accident Analysis \& Prevention, vol. 91, pp. 190-199, 2016.

[59] H. Ahangari, J. Outlaw, C. Atkinson-Palombo, and N. W. Garrick, "Investigation into impact of fluctuations in gasoline prices and macroeconomic conditions on road safety in developed countries," Transportation Research Record: Journal of the Transportation Research Board, vol. 2465, no. 1, pp. 48-56, 2014.

[60] G. W. Mercer, "Influences on passenger vehicle casualty accident frequency and severity: unemployment, driver gender, driver age, drinking driving and restraint device use," Accident Analysis \& Prevention, vol. 19, no. 3, pp. 231-236, 1987.

[61] F. Naznin, G. Currie, D. Logan, and M. Sarvi, “Application of a random effects negative binomial model to examine tram-involved crash frequency on route sections in Melbourne, Australia," Accident Analysis \& Prevention, vol. 92, pp. 15-21, 2016.

[62] A. Hadayeghi, A. S. Shalaby, and B. N. Persaud, "Safety prediction models," Transportation Research Record: Journal of the Transportation Research Board, vol. 2019, no. 1, pp. 225-236, 2007.

[63] S. S. Pulugurtha, V. R. Duddu, and Y. Kotagiri, "Traffic analysis zone level crash estimation models based on land use characteristics," Accident Analysis \& Prevention, vol. 50, pp. 678-687, 2013.

[64] Y. Wang and K. M. Kockelman, "A Poisson-lognormal conditional-autoregressive model for multivariate spatial analysis of pedestrian crash counts across neighborhoods," Accident Analysis \& Prevention, vol. 60, pp. 71-84, 2013.

[65] Victorian Government, DataVic, Victorian Government, Victoria, Australia, 2020, https://www.data.vic.gov.au/.

[66] Australian Bureau of Statistics, Australian Statistical Geography Standard (ASGS), Australian Bureau of Statistics, Canberra, Australia, 2016, https://www.abs.gov.au/ AUSSTATS/abs@.nsf/Lookup/1270.0.55. 001Main+Features10018July\%202016?OpenDocument..

[67] ESRI Environmental Systems Research Institute, California, FL, USA, 2019.

[68] S. Menard, Applied logistic regression analysis, Vol. 106, Sage, CA, USA, 2002. 
[69] P. A. P. Moran, "Notes on continuous stochastic phenomena," Biometrika, vol. 37, no. 1/2, pp. 17-23, 1950.

[70] R. Bivand, E. J. Pebesma, and V. Gómez-Rubio, Applied Spatial Data Analysis with R, Springer, New York, NY, USA, 2nd edition, 2013.

[71] R Core Team, R: A Language and Environment for Statistical Computing, R Foundation for Statistical Computing, Vienna, Austria, 2021, https://www.R-project.org/.

[72] S. Washington, M. Karlaftis, and F. Mannering, Statistical and Econometric Methods for Transportation Data Analysis, Chapman \& Hall/CRC, Boca Raton, FL, second ed edition, 2011.

[73] W. N. Venables and B. D. Ripley, "Random and mixed effects," in Modern Applied Statistics with S, pp. 271-300, Springer, NY, USA, 2002.

[74] R. Bivand and G. Piras, "Comparing Implementations of Estimation Methods for Spatial Econometrics," Journal of Statistical Software, vol. 63, 2015.

[75] T. Hothorn, F. Bretz, P. Westfall et al., Package 'multcomp'. Simultaneous Inference in General Parametric Models, Project for Statistical Computing, Vienna, Austria, 2016.

[76] R. Z. Koshy and V. T. Arasan, "Influence of bus stops on flow characteristics of mixed traffic," Journal of Transportation Engineering, vol. 131, no. 8, pp. 640-643, 2005.

[77] R. Goel and G. Tiwari, "Access-egress and other travel characteristics of metro users in Delhi and its satellite cities," IATSS Research, vol. 39, no. 2, pp. 164-172, 2016.

[78] I. Savage, "Comparing the fatality risks in United States transportation across modes and over time," Research in Transportation Economics, vol. 43, no. 1, pp. 9-22, 2013.

[79] G. Currie and A. Shalaby, "Success and challenges in modernizing streetcar systems," Transportation Research Record: Journal of the Transportation Research Board, vol. 2006, no. 1, pp. 31-39, 2007.

[80] Austroads, The Road Safety Consequences of Changing Travel Modes, Austroads Research Report AP-R361/10, Sydney NSW, Australia, 2010

[81] H. Weliwitiya, G. Rose, and M. Johnson, "Bicycle train intermodality: effects of demography, station characteristics and the built environment," Journal of Transport Geography, vol. 74, pp. 395-404, 2019.

[82] DOT Department of Transport, Car Park for Commuters, Department of Transport, Victoria, Australia, 2018. 